\title{
Endothelial cell counts after Descemet's stripping automated endothelial keratoplasty versus penetrating keratoplasty in Asian eyes
}

This article was published in the following Dove Press journal:

Clinical Ophthalmology

2 April 2012

Number of times this article has been viewed

Marcus Ang ${ }^{1,2}$

Jodhbir S Mehta ${ }^{1-4}$

Arundhati Anshu' ${ }^{1,2}$

Hon Kiat Wong ${ }^{5}$

Hla M Htoon ${ }^{2}$

Donald Tan ${ }^{1-3}$

'Singapore National Eye Centre, ${ }^{2}$ Singapore Eye Research Institute, ${ }^{3}$ Department of Ophthalmology, National University Health Systems, ${ }^{4}$ Department of Clinical Sciences, Duke-NUS Graduate Medical School, ${ }^{5}$ Department of Ophthalmology, Tan Tock Seng Hospital, Singapore
Correspondence: Donald Tan Singapore National Eye Centre, II Third Hospital Avenue, Singapore 16875 I

Tel +65 62277255

Fax +6563231903

Email snecdt@pacific.net.sg
Background: The purpose of this study was to compare endothelial cell counts after Descemet's stripping automated endothelial keratoplasty (DSAEK) and penetrating keratoplasty in Asian eyes.

Methods: This was a retrospective study of patients from our prospective Singapore Corneal Transplant Study cohort who received corneal transplantation in 2006-2008. We compared eyes that underwent DSAEK or penetrating keratoplasty for Fuchs' endothelial dystrophy or pseudophakic and aphakic bullous keratopathy. Clinical data, and donor and recipient characteristics were recorded. Of 241 patients who met our inclusion criteria, 68 underwent DSAEK and 173 underwent penetrating keratoplasty. The main outcome measure was endothelial cell loss at 1 year. Secondary outcome measures were graft survival and visual outcomes at 1 -year follow-up.

Results: There were no significant differences in baseline characteristics of patients between the treatment groups. Percent endothelial cell loss at 1-year follow-up was greater in penetrating keratoplasty eyes $(40.9 \% \pm 2.9 \%)$ compared with DSAEK eyes $(22.4 \% \pm 2.3 \%$; $P<0.001)$. DSAEK-treated eyes had significantly superior uncorrected visual acuity (mean difference $=0.42 \pm 0.0059 ; P<0.001$ ) and best spectacle-corrected visual acuity (mean difference $=0.14 \pm 0.032 ; P<0.001)$ as compared with penetrating keratoplasty-treated eyes. Penetrating keratoplasty-treated eyes had worse astigmatism as compared with DSAEK-treated eyes $(-3.0 \pm 2.1$ versus $-1.7 \pm 0.8 ; P<0.001)$. Graft survival at 1 year was comparable in both groups, ie, 66/68 (97.0\%) DSAEK-treated eyes versus $158 / 173(92.0 \%)$ of penetrating keratoplasty-treated eyes had clear grafts $(P=0.479)$.

Conclusion: We report lower percent endothelial cell loss comparing DSAEK and penetrating keratoplasty at 1-year follow-up in Asian eyes, with comparable graft survival rates in both groups.

Keywords: Descemet's stripping automated endothelial keratoplasty, endothelial cell count, penetrating keratoplasty

\section{Introduction}

Corneal transplantation for corneal endothelial diseases is undergoing a paradigm shift from penetrating keratoplasty to endothelial keratoplasty. ${ }^{1}$ Descemet's stripping automated endothelial keratoplasty (DSAEK), which is essentially endothelial keratoplasty that involves donor tissue preparation using an automated microkeratome, is rapidly becoming the preferred alternative to conventional penetrating keratoplasty for endothelial dysfunction, such as Fuchs' endothelial keratoplasty and pseudophakic bullous keratopathy. ${ }^{2}$ In the United States, the number of donor corneas for endothelial keratoplasty has exponentially increased from 3\% (2005) to 33\% (2007) and 42.8\% 
in 2009 (Eye Banking Statistical Report 2009, Eye Bank Association of America data (http://www.restoresight.org/ donation/statistics.htm).

The advantages of DSAEK over penetrating keratoplasty include better tectonic stability, essentially sutureless surgery, and faster postoperative visual rehabilitation with more predictable refractive changes. ${ }^{3-7}$ However, early studies mainly in Caucasian eyes suggest equivalent or higher cell loss in DSAEK compared to penetrating keratoplasty at 6 months, albeit nonsignificant by 2 years. ${ }^{3,8-12}$

The main aim of this study was to compare our DSAEK results in terms of endothelial cell loss with those of penetrating keratoplasty with at least 1-year follow-up in Asian eyes using our previously described DSAEK technique. ${ }^{13}$

\section{Materials and methods}

We conducted a retrospective study of patients who underwent DSAEK or penetrating keratoplasty for which the surgical indication was either Fuchs' endothelial dystrophy or pseudophakic and aphakic bullous keratopathy in 2006-2008. We excluded any patients who did not have a minimum pos-surgical follow-up of 1 year. Our subjects and clinical data were obtained from the ongoing cohort of the Singapore Corneal Transplant Study, an audited longitudinal prospective study which contains preoperative, intraoperative, and yearly postoperative follow-up clinical data. ${ }^{14}$ This study followed the principles of the Declaration of Helsinki, with ethics approval obtained from our institutional review board. A total of 241 patients met our inclusion criteria, of whom 68 underwent DSAEK and 173 underwent penetrating keratoplasty by the five corneal surgeons at our center, as well as inclusion of cases which were partially performed by corneal fellows in training under direct supervision.

We reviewed patient demographics, clinical features, and surgical techniques. Our main outcome measure was endothelial cell count and the derived percent endothelial cell loss at 1 year follow-up. Our secondary outcome measures included graft success and visual acuity at 1 year follow-up. Visual acuity was measured using the Snellen visual acuity chart and we analyzed the results using logarithm of the minimum angle of resolution (logMAR) equivalent units, including manifest refraction, spherical equivalent, and cylindrical error. ${ }^{15}$ The Singapore Eye Bank provides all donor corneas, stored in OptisolTM in cold storage, with standard internal guidelines for penetrating keratoplasty and DSAEK grafts and we obtained all donor information from their database, including donor endothelial cell counts. ${ }^{14}$
Preoperative specular microscopy of the donor tissue was performed either by certified technicians in an Eye Bank Association of America-certified eye bank or by a certified eye bank technician at the Singapore Eye Bank. Postoperative specular microscopy measurements of endothelial cell density were performed using a noncontact specular microscope (Konan Medical Corporation, Hyogo, Japan) at 12 months postoperatively, by ophthalmic technicians trained in specular microscopy. Calibrations and magnifications were standardized automated measurements with a mean value derived, as previously described. ${ }^{16}$ The incidence of postoperative complications was obtained from the Singapore Corneal Transplant Study database, which tracks all graft complications. Graft failure was defined as irreversible loss of optical clarity, with the date of onset of corneal clouding selected as the time point of graft failure.

\section{Surgical technique}

Penetrating keratoplasty surgeries were performed using a standard technique based on a Hanna vacuum trephine system (Moria Inc, Antony, France). In summary, the recipient cornea was excised using the Hanna trephine. A $0.25-0.50 \mathrm{~mm}$ oversized donor cornea was then punched out endothelial side up and sutured on to the recipient with 10-0 nylon, using either an 8-bite, 10-0 nylon double continuous running suture or a combination of a single 8-bite 10-0 nylon continuous and eight interrupted sutures. Intraoperative astigmatic control was achieved using a microscope-mounted keratoscope. A bandage contact lens was placed at the end of the surgery, and subconjunctival dexamethasone $0.1 \%$ (Decadron ${ }^{\circledR}$; Merck and Co, Inc, Rahway, NJ), gentamicin $14 \mathrm{mg} / \mathrm{mL}$ (Garamycin ${ }^{\circledR}$; Schering AG, Berlin-Wedding, Germany), and cefazolin 50 mg/mL (Ancef ${ }^{\circledR}$; GlaxoSmithKline, Research Triangle Park, NC) was injected.

DSAEK was performed using our previously described technique. ${ }^{13,16}$ Essentially, after Descemet's stripping under air, ${ }^{17}$ a paracentesis was first made in the peripheral cornea opposite the scleral tunnel wound for insertion of Kawai intraocular capsulorhexis forceps (Asico, Westmont, IL) or Tan DSAEK forceps (Asico). ${ }^{13}$ A standard anterior chamber intraocular lens sheets glide (BD Visitec ${ }^{\mathrm{TM}}$ ) was trimmed to $4.5 \mathrm{~mm}$ and inserted into the eye through a $5 \mathrm{~mm}$ temporal scleral tunnel incision while the anterior chamber was maintained via an anterior chamber maintainer with a balanced salt solution infusion. An inferior peripheral iridectomy was performed through a limbal stab incision. The donor was prepared by the surgeon using an automated lamellar therapeutic keratoplasty system (ALTK; Moria SA, 
Antony, France) aiming for a donor cornea of thickness of approximately 150 microns. Four preplaced corneal venting incisions were made on the recipient cornea. A dispersive ophthalmic viscosurgical device (VisCoat ${ }^{\mathbb{R}}$; Alcon Laboratories Inc, Hünenberg, Switzerland) was liberally applied over the endothelial surface of the donor cornea and on the anterior surface of the glide, taking care not to have the ophthalmic viscosurgical device on the stromal donor surface. The donor cornea was gently inverted, corneal endothelial surface-down, onto the ophthalmic viscosurgical device covered portion of the glide. Kawai or Tan DSAEK forceps were passed through the nasal paracentesis, over the sheets glide, and out through the scleral incision, grasping the donor cornea stromal edge and pulling the donor cornea through the scleral incision, whilst the anterior chamber maintainer was infusing balanced salt solution at a medium to slow rate. With this technique, a deep chamber was maintained throughout the maneuver. A small air bubble was injected under the donor cornea with a 30-gauge canula to prevent descent of the donor cornea, the sheets glide retracted, and the donor cornea was released from the forceps. The scleral tunnel was then sutured with three $10 / 0$ nylon interrupted sutures, the anterior chamber maintainer was removed and the port sutured, the donor was adjusted centrally by gentle massage through the cornea surface, and full air tamponade was achieved with a large bubble in the anterior chamber for 8 minutes. Following this, some air was replaced with balanced salt solution, leaving a smaller air bubble approximating the size of the endothelial keratoplasty graft in the anterior chamber. Subconjunctival steroid and antibiotic injections and a bandage contact lens completed the procedure. All patients were examined approximately one hour after surgery to ensure air was still present in the anterior chamber, and no donor dislocation or pupillary block was present. We used similar postoperative medication regimens in both groups, ie, Predforte ${ }^{\circledR}$ (prednisolone acetate ophthalmic suspension, USP) $1 \%$ every 3 hours for 1 week, three times a day for 6 months, twice daily for 3 months then once a day for up to 1 year.

\section{Statistical analysis}

Statistical analysis included descriptive statistics, whereby the mean and standard deviation were calculated for the continuous variables, while the frequency distribution and percentages were used for categorical variables. Comparisons between categorical variables were conducted using Fisher's exact tests, whereas the one-way analysis of variance test was used for means. Kaplan-Meier survival analysis was conducted to determine survival probabilities of penetrating keratoplasty and DSAEK groups. The survival period of failed grafts was defined as the time between the date of surgery and recorded date of survival or failure. The estimate of odds ratio and its relative $95 \%$ confidence interval was calculated. A $P$ value $<0.05$ was considered statistically significant.

\section{Results Recipient characteristics}

The demographics and clinical characteristics of our study cohort are summarized in Table 1. Overall, there were more patients whose main surgical indication was bullous keratopathy as compared with Fuchs' dystrophy (153/241, $63.5 \%$ ) and more of the patients with bullous keratopathy had undergone a penetrating keratoplasty as compared with DSAEK $(120 / 173,69.4 \%$ versus $33 / 68,48.5 \%$; $P=0.003)$. However, there were no significant differences in demographics or characteristics of patients with bullous keratopathy or Fuchs' dystrophy between the treatment groups.

\section{Endothelial cell counts}

The mean preoperative donor endothelial cell density was 101 cells $/ \mathrm{mm}^{2}$ greater in the DSAEK than in the penetrating keratoplasty group $\left(2792 \pm 327\right.$ versus $2691 \pm 360$ cells $/ \mathrm{mm}^{2}$; $P=0.0412$ ). Donor size was significantly larger in patients undergoing DSAEK as compared with penetrating keratoplasty (mean donor size $8.75 \pm 0.49$ versus $7.87 \pm 0.34 \mathrm{~mm}$; $P<0.001)$. Postoperative endothelial cell density was obtainable in 120 eyes (60 DSAEK-treated eyes and 60 penetrating keratoplasty-treated eyes) performed at 1-year follow-up. In this subanalysis, there were no significant differences in baseline characteristics, such as mean recipient age (64 \pm 10 versus $67 \pm 11$ years; $P=0.08) \operatorname{sex}(P=0.06)$, race $(P=0.16)$, or diagnosis (51\% versus 49\% Fuchs' dystrophy; $P=0.86$ ) between the DSAEK and penetrating keratoplasty groups. We found that mean endothelial cell density was greater at 1 year in the DSAEK group as compared with the penetrating keratoplasty group $(2174 \pm 66$ versus $1555 \pm 76 ; P=0.001)$ and overall percentage of endothelial cell loss after 1 year was $40.9 \% \pm 2.9 \%$ in penetrating keratoplasty-treated and $22.4 \% \pm 2.3 \%$ in DSAEK-treated eyes $(P<0.001)$. In patients with Fuchs' dystrophy, DSAEK-treated eyes had significantly less percentage of endothelial cell loss compared with penetrating keratoplasty-treated eyes (30 eyes each group, mean percentage endothelial cell loss; $20.4 \% \pm 1.4 \%$ versus $37.7 \% \pm 2.3 \%$; $P=0.001)$. This was similar to patients with bullous keratopathy (30 eyes each group, mean percentage of endothelial cell loss; 
Table I Characteristics of patients (overall, penetrating keratoplasty, and DSAEK)

\begin{tabular}{|c|c|c|c|c|}
\hline \multirow[t]{2}{*}{ Characteristics } & \multicolumn{3}{|c|}{ Corneal graft } & \multirow[t]{2}{*}{$P$ value $^{\mathrm{a}}$} \\
\hline & $\begin{array}{l}\text { Total } \\
(n=24 I)\end{array}$ & $\begin{array}{l}P K \\
(n=173)\end{array}$ & $\begin{array}{l}\text { DSAEK } \\
(n=68)\end{array}$ & \\
\hline Mean age, years $( \pm S D)$ & $67.5(11.3)$ & $68.4(10.0)$ & $65.3(13.7)$ & 0.062 \\
\hline \multicolumn{5}{|l|}{ Gender (\%) } \\
\hline Male & $118(49.0)$ & $82(47.4)$ & $36(52.9)$ & \multirow[t]{2}{*}{0.476} \\
\hline Female & $123(51.0)$ & $91(52.6)$ & $32(47.1)$ & \\
\hline \multicolumn{5}{|l|}{ Race (\%) } \\
\hline Chinese & $207(85.9)$ & $162(93.6)$ & $45(66.2)$ & \multirow[t]{5}{*}{0.001} \\
\hline Malay & $13(5.4)$ & $10(5.8)$ & $3(4.4)$ & \\
\hline Indian & $3(1.2)$ & 0 & $3(4.4)$ & \\
\hline Caucasian & $2(6.2)$ & 0 & $2(2.9)$ & \\
\hline Others & $16(6.6)$ & I $(0.58)$ & $15(22.1)$ & \\
\hline \multicolumn{5}{|l|}{ Primary indication } \\
\hline Fuchs' dystrophy & $88(36.5)$ & $53(30.6)$ & $35(5 \mathrm{I} .5)$ & \multirow[t]{3}{*}{0.003} \\
\hline Pseudophakic/aphakic & $153(63.5)$ & $120(69.4)$ & $33(48.5)$ & \\
\hline bullous keratopathy & & & & \\
\hline \multicolumn{5}{|l|}{ Type of surgery } \\
\hline Graft alone & $146(60.6)$ & $90(52.0)$ & $56(82.4)$ & 0.03 \\
\hline Graft + cataract extraction + IOL & $52(21.6)$ & $44(25.3)$ & $8(I I .8)$ & 0.02 \\
\hline Graft + cataract extraction $+\mathrm{ACIOL}$ & $12(5.0)$ & $10(5.8)$ & $2(3.0)$ & 0.518 \\
\hline Graft + secondary IOL implant & $6(2.5)$ & $5(2.9)$ & $\mathrm{I}(\mathrm{I} .5)$ & 0.524 \\
\hline Anterior vitrectomy & $20(8.3)$ & $19(11.0)$ & $\mathrm{I}(\mathrm{I} .5)$ & 0.004 \\
\hline \multicolumn{5}{|l|}{ Visual acuity ${ }^{\mathrm{b}}$ (logMAR) } \\
\hline Preoperative visual acuity (mean, SD) & $1.77(0.76)$ & $\mathrm{I} .86(0.42)$ & $1.56(0.66)$ & 0.001 \\
\hline Postoperative UCVA (mean, SD) & $0.64(0.47)$ & $0.78(0.50)$ & $0.33(0.18)$ & 0.001 \\
\hline Postoperative BCVA (mean, SD) & $0.37(0.34)$ & $0.42(0.19)$ & $0.27(0.17)$ & 0.001 \\
\hline Percent change in visual acuity $(\%, S D)$ & $69.4(25.1)$ & $68.3(25.7)$ & $71.8(23.7)$ & 0.376 \\
\hline \multicolumn{5}{|l|}{ Refractive outcome ${ }^{c}$} \\
\hline Sphere, diopter (mean, SD) & $+0.17(2.8)$ & $-0.021(3.2)$ & $+0.62(1.8)$ & 0.166 \\
\hline Cylinder, diopter (mean, SD) & $-2.6(1.9)$ & $-3.0(2.1)$ & $-1.7(0.8 \mathrm{I})$ & 0.001 \\
\hline Spherical equivalent (mean, SD) & $-1.3(3.0)$ & $-1.5(3.3)$ & $-0.25(1.8)$ & 0.001 \\
\hline Percent ECD loss' $(\%, S D)$ & $31.7(2.2)$ & $40.0(2.3)$ & $22.4(1.8)$ & 0.001 \\
\hline Number of graft failures at I yeard $(\%)$ & $17(7.1)$ & $15(8.0)$ & $2(3.0)$ & 0.118 \\
\hline
\end{tabular}

Notes: ${ }^{a} P$ value from one-way analysis of variance or Chi-square test as appropriate; ${ }^{b}$ number of patients with valid visual acuity $\left(n=198 ;\right.$ PK $=137$, DSAEK $=6 \mathrm{I}$ ); ${ }^{c}$ number of patients with valid endothelial cell counts $(n=120$; PK $=60$, DSAEK $=60)$; ${ }^{d}$ graft failure defined as irreversible loss of optical clarity, with the date of onset of corneal clouding selected as the time point of graft failure.

Abbreviations: ACIOL, anterior chamber intraocular lens; PK, penetrating keratoplasty; DSAEK, Descemet's stripping automated endothelial keratoplasty; VA, visual acuity; BCVA, best-corrected visual acuity; UCVA, uncorrected visual acuity; ECD, endothelial cell density; SD, standard deviation; IOL, intraocular lens.

$24.2 \% \pm 2.0 \%$ versus $41.8 \% \pm 2.2 \% ; P=0.002)$. We also compared percentage of endothelial cell loss at 1 year between patients with Fuchs' dystrophy and bullous keratopathy. At 1 year, the percentage of endothelial cell loss did not differ significantly between patients with Fuchs' dystrophy and those with bullous keratopathy for either procedure (39\% versus $44 \%$ in penetrating keratoplasty-treated eyes; $P=0.40$; and $20 \%$ versus $24 \%$ in DSAEK-treated eyes; $P=0.45$ ).

\section{Visual acuity outcomes at I year}

In our study cohort, 26 patients had concomitant eye disease, which significantly impacted on final visual outcome, while 17 patients had late graft failure at 1 year. All these patients were excluded from our final visual acuity analysis (Table 2). We compared the remaining patients (61 DSAEK with 137 penetrating keratoplasty-treated eyes) with respect to visual acuity. Amongst these patients there were fewer patients who had Fuchs' dystrophy in the penetrating keratoplasty group (35/61 [57.3\%] DSAEK; 51/137 [37.2\%] penetrating keratoplasty; $P=0.011)$. Sutures remained in place for all penetrating keratoplasty-treated eyes.

Patients who underwent DSAEK had better visual outcomes at 1 year when compared with penetrating keratoplastytreated patients (Table 3). Overall, DSAEK-treated eyes had significantly superior uncorrected visual acuity (UCVA) and best spectacle-corrected visual acuity (BSCVA) as compared with penetrating keratoplasty-treated eyes at 1 year (mean difference UCVA, $0.42 \pm 0.0059$; $P<0.001$; BSCVA, $0.14 \pm 0.032 ; P<0.001)$. In addition, there were more eyes with BSCVA better than 20/40 in DSAEK-treated 
Table 2 Patients excluded from visual outcome analysis

\begin{tabular}{llll}
\hline $\begin{array}{l}\text { Concomitant } \\
\text { diseases }\end{array}$ & $\begin{array}{l}\text { PK-treated } \\
\text { eyes }\end{array}$ & $\begin{array}{l}\text { DSAEK-treated } \\
\text { eyes }\end{array}$ & $\begin{array}{l}\text { Percent } \\
\text { (\%) }\end{array}$ \\
\hline AMD & 2 & 3 & 11.6 \\
Macular scar & 4 & 3 & 16.3 \\
Advanced glaucoma & 3 & 4 & 16.3 \\
$\begin{array}{l}\text { Advanced diabetic } \\
\text { retinopathy }\end{array}$ & 2 & 2 & 9.3 \\
Graft failure at I year & 15 & 2 & 39.5 \\
Others & 2 & 1 & 7.0 \\
Total & 28 & 15 & 100 \\
\hline
\end{tabular}

Abbreviations: PK, penetrating keratoplasty; DSAEK, Descemet's stripping automated endothelial keratoplasty; AMD, age-related macular degeneration.

group as compared with the penetrating keratoplasty-treated group $(67.2 \%$ versus $38.7 \% ; P<0.001)$. When comparing visual outcomes between surgical indications, we found that visual outcome was significantly better in eyes with Fuchs' dystrophy for both DSAEK (mean difference BSCVA, $0.36 \pm 0.011 ; P=0.002$ ) and penetrating keratoplasty (mean difference BSCVA, $0.40 \pm 0.0079 ; P<0.001)$.

\section{Refractive outcomes at I year}

Overall, patients with penetrating keratoplasty-treated eyes had higher astigmatism at 1 year as compared with DSAEK-treated eyes $(-3.0 \pm 2.1$ versus $-1.7 \pm 0.8$, respectively; $P<0.001$, Table 1). We also observed this difference in patients with Fuchs' dystrophy $(-2.6 \pm 1.8$ versus $-1.7 \pm 0.8 ; P=0.023)$ and bullous keratopathy $(-3.2 \pm 2.2$ versus $-1.7 \pm 0.8 ; P=0.001$, Table 3$)$. Overall, DSAEK-treated eyes were more hyperopic as compared with penetrating keratoplasty-treated eyes at 1 year (spherical equivalent $+1.5 \pm 3.3$ versus $-0.25 \pm 1.8$, respectively; $P<0.001)$.

\section{Graft success}

We had one case of primary graft failure in each of the DSAEK and penetrating keratoplasty treatment groups ( $1 / 68$, $1.5 \%$ versus $1 / 173,0.5 \%$ respectively; $P=0.31$ ). At 1 year, $66 / 68(97.0 \%)$ eyes that underwent DSAEK had clear grafts while $158 / 173(92.0 \%)$ of penetrating keratoplasty-treated eyes had clear grafts $(P=0.479)$. There were no significant differences in late graft failure between the groups (penetrating keratoplasty $8 \%$ versus DSAEK $3 \% ; P=0.118$ ). Reasons for graft failure in the penetrating keratoplasty group were infection-related $(\mathrm{n}=10)$ and immune-related $(\mathrm{n}=5)$; and for the DSAEK group were immune-related $(\mathrm{n}=2)$. The Kaplan-Meier probability of survival at 1 year was $95.3 \%$ for the penetrating keratoplasty-treated group, which decreased to $89.6 \%$ at 18 months, while it was $98.4 \%$ at 1 year and $93.2 \%$ for DSAEK cases up to 18 months of follow-up $(P<0.001)$.

Table 3 Outcomes of patients (PK and DSAEK) subdivided into Fuchs' dystrophy and pseudophakic/aphakic bullous keratopathy

\begin{tabular}{|c|c|c|c|}
\hline \multirow[t]{2}{*}{ Characteristics } & \multicolumn{2}{|c|}{ Corneal graft } & \multirow[t]{2}{*}{$P$ value } \\
\hline & $\begin{array}{l}P K \\
(n=137)\end{array}$ & $\begin{array}{l}\text { DSAEK } \\
(n=61)\end{array}$ & \\
\hline \multicolumn{4}{|l|}{ Fuchs' dystrophy $(n=86)$} \\
\hline \multicolumn{4}{|l|}{ Visual acuity ${ }^{\mathrm{b}}$ (logMAR) } \\
\hline Preoperative visual acuity (mean, SD) & $1.29(0.67)$ & $1.02(0.56)$ & 0.001 \\
\hline Postoperative UCVA (mean, SD) & $0.80(0.59)$ & $0.37(0.35)$ & 0.011 \\
\hline Postoperative BCVA (mean, SD) & $0.45(0.36)$ & $0.26(0.19)$ & 0.003 \\
\hline Percent change in visual acuity $(\%, S D)$ & $54.1(43.2)$ & $69.1(24.5)$ & 0.376 \\
\hline \multicolumn{4}{|l|}{ Refractive outcome ${ }^{b}$} \\
\hline Sphere, diopter (mean, SD) & $-0.043(3.0)$ & $+0.49(2.1)$ & 0.384 \\
\hline Cylinder, diopter (mean, SD) & $-2.6(1.8)$ & $-1.7(0.84)$ & 0.023 \\
\hline Spherical equivalent (mean, SD) & $-1.6(3.2)$ & $-0.38(2.1)$ & 0.052 \\
\hline \multicolumn{4}{|c|}{ Pseudophakic/aphakic bullous keratopathy $(n=|| 2)$} \\
\hline \multicolumn{4}{|l|}{ Visual acuity ${ }^{\mathrm{b}}(\log M A R)$} \\
\hline Preoperative visual acuity (mean, SD) & $1.94(0.43)$ & $1.29(0.67)$ & 0.001 \\
\hline Postoperative UCVA (mean, SD) & $1.15(0.86)$ & $0.80(0.59)$ & 0.001 \\
\hline Postoperative BCVA (mean, SD) & $0.84(0.66)$ & $0.44(0.36)$ & 0.001 \\
\hline Percent change in visual acuity $(\%, S D)$ & $54.0(42.3)$ & $54.1(43.2)$ & 0.982 \\
\hline \multicolumn{4}{|l|}{ Refractive outcome ${ }^{\mathrm{b}}$} \\
\hline Sphere, diopter (mean, SD) & $+0.024(2.9)$ & $+0.74(\mathrm{I} . \mathrm{I})$ & 0.320 \\
\hline Cylinder, diopter (mean, SD) & $-3.2(2.2)$ & $-1.7(0.80)$ & 0.001 \\
\hline Spherical equivalent (mean, SD) & $-1.3(3.5)$ & $-0.12(1.4)$ & 0.113 \\
\hline
\end{tabular}

Notes: ${ }^{a} P$ value from one-way analysis of variance or Chi-square test as appropriate; ${ }^{\text {nnumber }}$ of patients with valid visual acuity $(n=198 ;$ PK $=137$, DSAEK $=61)$. Abbreviations: PK, penetrating keratoplasty; DSAEK, Descemet's stripping automated endothelial keratoplasty; VA, visual acuity; BCVA, best-corrected visual acuity; UCVA, uncorrected visual acuity; SD, standard deviation. 


\section{Complications}

Complications during the 1-year follow-up period were recorded according to our Singapore Corneal Transplant Study guidelines. ${ }^{14}$ We scored complications as events and made comparisons between the penetrating keratoplasty and DSAEK groups (Table 4). ${ }^{18}$ Epitheliopathy was significantly higher in penetrating keratoplasty-treated eyes $(P=0.014)$, while transient episodes of intraocular pressure elevation $>21 \mathrm{mmHg}$ (defined in terms of short-term, ie, $\leq 3$ months use of antiglaucoma medications) were seen in 20/68 (29.4\%) and 52/173 (30.0\%) for DSAEK and penetrating keratoplasty, respectively $(P=0.93)$. Of note, most of these patients (16/20 [80.0\%] for DSAEK and 49/52 [94.2\%] for penetrating keratoplasty) had an underlying history of glaucoma $(P=0.07)$. Only four eyes (three penetrating keratoplasty, one DSAEK) had had trabeculectomy performed previously, and there were no significant differences in graft outcomes. All eyes with transiently raised intraocular pressure were treated successfully with intraocular pressurelowering topical and/or systemic medications. One patient who underwent DSAEK had an acute graft rejection episode successfully treated with topical steroids, as compared with $11(6.3 \%)$ in the penetrating keratoplasty-treated group. Of note, we had no graft dislocations in our DSAEK-treated eyes in this series of patients.

\section{Discussion}

In this study we found that 1-year percentage of endothelial cell loss and visual outcomes were superior in DSAEK-treated eyes as compared with penetrating keratoplasty-treated eyes from the same study cohort, which confirms the results of our preliminary study on DSAEK in Asian eyes. ${ }^{16}$ This is in contrast with reports in the literature that DSAEK has greater endothelial cell loss compared with penetrating keratoplasty, but few of these studies reported data on endothelial cell loss beyond 12 months of follow-up and none were directly compared with penetrating keratoplasty from the same study cohort., ${ }^{3,8-12}$ One study compared subjects from their prospective trial on DSAEK with a separate study on penetrating keratoplasty from the Specular Microscopy Ancillary Study cohort. ${ }^{19}$ Another study found that 1-year endothelial cell density was lower with DSAEK compared with penetrating keratoplasty albeit but the difference was not statistically significant. ${ }^{20}$ This led to the conclusion in a recent review article that there is currently insufficient evidence to conclude whether endothelial cell loss is greater in DSAEK. ${ }^{21}$ The results from this study are encouraging because our endothelial cell loss at 1 year $(22.4 \% \pm 2.3 \%)$ using a sheets glide
Table 4 Complications of PK and DSAEK within I-year follow-up

\begin{tabular}{|c|c|c|c|}
\hline Complications & $\begin{array}{l}\text { DSAEK } \\
\text { n (\%) }\end{array}$ & $\begin{array}{l}\text { PK } \\
\text { n (\%) }\end{array}$ & $P$ value ${ }^{a}$ \\
\hline $\begin{array}{l}\text { Transient elevated IOP } \\
(>21 \mathrm{mmHg})\end{array}$ & $20(29.4)$ & $52(30.0)$ & 0.929 \\
\hline Epitheliopathy & 0 & $23(13.3)$ & 0.014 \\
\hline Graft rejection episode & $\mathrm{I}(\mathrm{I} .5)$ & II (6.3) & 0.690 \\
\hline Late graft failure & $2(3.0)$ & $15(8.0)$ & 0.118 \\
\hline Resuture & 0 & $8(2.9)$ & 0.352 \\
\hline Wound dehiscence & 0 & $4(2.3)$ & 1.000 \\
\hline Corneal infection & $\mathrm{I}(\mathrm{I} .5)$ & $2(1.1)$ & 0.424 \\
\hline Primary graft failure & $\mathrm{I}(\mathrm{I} .5)$ & $\mathrm{I}(0.5)$ & 0.307 \\
\hline $\begin{array}{l}\text { Recurrence of } \\
\text { primary disease }\end{array}$ & 0 & $\mathrm{I}(0.5)$ & 1.000 \\
\hline $\begin{array}{l}\text { Reactivation of } \\
\text { herpetic infection }\end{array}$ & 0 & $\mathrm{I}(0.5)$ & 1.000 \\
\hline Anterior synechiae & 0 & $\mathrm{I}(0.5)$ & 1.000 \\
\hline $\begin{array}{l}\text { Graft detachment } \\
\text { and repositioning }\end{array}$ & 0 & 0 & - \\
\hline Suprachoroidal hemorrhage & 0 & 0 & - \\
\hline Endophthalmitis & 0 & 0 & - \\
\hline
\end{tabular}

Note: a Chi-square of Fisher's exact test as appropriate.

Abbreviations: IOP, intraocular pressure; PK, penetrating keratoplasty; DSAEK, Descemet's stripping automated endothelial keratoplasty.

nonfolding technique was comparable with other non-folding techniques, and we were able to show less endothelial cell loss comparable with penetrating keratoplasty from a same cohort of patients. Although our endothelial cell loss is less than that using a taco-folding technique, ${ }^{22}$ longer follow-up is required to confirm if we have a similar endothelial cell loss trend. Another advantage of performing DSAEK over penetrating keratoplasty is the ability to use a larger donor size, and thus transplant more endothelial cells. ${ }^{4}$ In our study, the mean donor size was 10\% larger and endothelial cell density was greater in the DSAEK group than in the penetrating keratoplasty group $(P<0.001)$.

The percentage endothelial cell loss, visual outcomes, and astigmatism in eyes with Fuchs' dystrophy and bullous keratopathy treated with penetrating keratoplasty in our study of Asian eyes were comparable with those of previous reports in Caucasian eyes. ${ }^{3,23-25}$ However, it may not be useful to compare visual outcomes at 1 year between DSAEK and penetrating keratoplasty due to the longer visual rehabilitation and use of sutures in penetrating keratoplasty, thus it was only a secondary outcome measure. Nonetheless, in our study, DSAEK had better postoperative UCVA and BSCVA as compared with penetrating keratoplasty, which was also found in Caucasian eyes but with fewer eyes (20 in each group). ${ }^{3,20}$ While this is somewhat expected, our results confirm that visual rehabilitation takes much longer after penetrating keratoplasty, even when comparing BSCVA 
at 1 year follow-up. In our study cohort there was a higher proportion of pseudophakic eyes amongst patients who had undergone DSAEK for Fuchs' dystrophy. This is because we adhere to the general policy that lens removal prior to DSAEK obviates the risk of subsequent cataract formation and also creates more space in the anterior chamber during DSAEK surgery. Moreover, more of the penetrating keratoplasty-treated eyes had complicated surgeries that required anterior vitrectomy and anterior chamber intraocular lens insertion. These factors could contribute to the poorer visual outcome and lower endothelial cell counts in the penetrating keratoplasty-treated group.

The main limitations of our study are due to its retrospective nature. Although our patients differed in their characteristics, such as demographics and phakic status, we matched subjects in each group for donor and recipient characteristics. We acknowledge that case selection between DSAEK and penetrating keratoplasty was dependent on surgeon choice, and that more severe or advanced cases of corneal decompensation were likely to have received penetrating keratoplasty surgery. However, we do routinely attempt DSAEK in severe cases of bullous keratopathy, as long as there is only moderate anterior stromal scarring present. This may have affected our postoperative visual outcome comparisons, although this would have minimal effect on differences in endothelial cell loss postoperatively between DSAEK and penetrating keratoplasty. Our study also had a limited follow-up period of 1 year in order to compare graft survival and record reliable endothelial cell count data, which was only obtained in 120 eyes. However, we analyzed eyes from each group matched for surgical indication to minimize selection bias and there were no significant baseline differences in each group. Nevertheless, due to the inherent success of DSAEK, it would be challenging and unethical in our institution to conduct a randomized controlled study given the clinical advantages of DSAEK over penetrating keratoplasty, hence a historical cohort of penetrating keratoplasty cases in the same population group using the same postoperative regime provided the best comparative cohort.

\section{Conclusion}

We found that performing DSAEK using the described technique in Asian eyes resulted in a lower 1-year endothelial percent cell loss as compared with penetrating keratoplasty for patients with Fuchs' dystrophy and bullous keratopathy. Graft survival was comparable in both groups at 1-year follow-up, although visual outcomes were superior in the DSAEK group with fewer complications. Longer follow-up will provide more data on endothelial cell loss with these two techniques. Improvements in donor insertion devices may reduce the initial ECC loss further and improve longterm ECC outcomes. ${ }^{26}$

\section{Disclosure}

The authors report no conflicts of interest in this work.

\section{References}

1. Tan DT, Anshu A, Mehta JS. Paradigm shifts in corneal transplantation. Ann Acad Med Singapore. 2009;38(4):332-338.

2. Price MO, Price FW Jr. Endothelial keratoplasty - a review. Clin Experiment Ophthalmol. 2010;38(2):128-140.

3. Lee WB, Jacobs DS, Musch DC, Kaufman SC, Reinhart WJ, Shtein RM. Descemet's stripping endothelial keratoplasty: safety and outcomes: a report by the American Academy of Ophthalmology. Ophthalmology. 2009;116(9):1818-1830.

4. Price MO, Price FW. Descemet's stripping endothelial keratoplasty. Curr Opin Ophthalmol. 2007;18(4):290-294.

5. Rao SK, Leung CK, Cheung CY, et al. Descemet's stripping endothelial keratoplasty: effect of the surgical procedure on corneal optics. $A m J$ Ophthalmol. 2008;145(6):991-996.

6. Price FW Jr, Price MO. Descemet's stripping with endothelial keratoplasty in 200 eyes: Early challenges and techniques to enhance donor adherence. J Cataract Refract Surg. 2006;32(3):411-418.

7. Price MO, Price FW Jr. Descemet's stripping with endothelial keratoplasty: comparative outcomes with microkeratome-dissected and manually dissected donor tissue. Ophthalmology. 2006;113(11): 1936-1942.

8. Price MO, Price FW Jr. Endothelial cell loss after descemet stripping with endothelial keratoplasty influencing factors and 2-year trend. Ophthalmology. 2008;115(5):857-865.

9. Busin M, Bhatt PR, Scorcia V. A modified technique for Descemet membrane stripping automated endothelial keratoplasty to minimize endothelial cell loss. Arch Ophthalmol. 2008;126(8):1133-1137.

10. Price MO, Fairchild KM, Price DA, Price FW Jr. Descemet's stripping endothelial keratoplasty five-year graft survival and endothelial cell loss. Ophthalmology. 2011;118(4):725-729.

11. Terry MA, Chen ES, Shamie N, Hoar KL, Friend DJ. Endothelial cell loss after Descemet's stripping endothelial keratoplasty in a large prospective series. Ophthalmology. 2008;115(3):488-496, e3.

12. Terry MA, Shamie N, Straiko MD, Friend DJ, Davis-Boozer D. Endothelial keratoplasty: the relationship between donor tissue storage time and donor endothelial survival. Ophthalmology. 2011;118(1):36-40.

13. Mehta JS, Por YM, Beuerman RW, Tan DT. Glide insertion technique for donor cornea lenticule during Descemet's stripping automated endothelial keratoplasty. J Cataract Refract Surg. 2007;33(11):1846-1850.

14. Tan DT, Janardhanan P, Zhou H, et al. Penetrating keratoplasty in Asian eyes: the Singapore Corneal Transplant Study. Ophthalmology. 2008; 115(6):975-998, e1.

15. Holladay JT. Visual acuity measurements. J Cataract Refract Surg. 2004;30(2):287-290.

16. Mehta JS, Por YM, Poh R, Beuerman RW, Tan D. Comparison of donor insertion techniques for descemet stripping automated endothelial keratoplasty. Arch Ophthalmol. 2008;126(10):1383-1388.

17. Mehta JS, Hantera MM, Tan DT. Modified air-assisted descemetorhexis for Descemet-stripping automated endothelial keratoplasty. J Cataract Refract Surg. 2008;34(6):889-891.

18. Han DC, Mehta JS, Por YM, Htoon HM, Tan DT. Comparison of outcomes of lamellar keratoplasty and penetrating keratoplasty in keratoconus. Am J Ophthalmol. 2009;148(5):744-751, e1.

19. Price MO, Gorovoy M, Benetz BA, et al. Descemet's stripping automated endothelial keratoplasty outcomes compared with penetrating keratoplasty from the Cornea Donor Study. Ophthalmology. 2010;117(3):438-444. 
20. Hjortdal J, Ehlers N. Descemet's stripping automated endothelial keratoplasty and penetrating keratoplasty for Fuchs' endothelial dystrophy. Acta Ophthalmol. 2009;87(3):310-314.

21. Nanavaty MA, Shortt AJ. Endothelial keratoplasty versus penetrating keratoplasty for Fuchs' endothelial dystrophy. Cochrane Database Syst Rev. 2011;7:CD008420.

22. Chen ES, Shamie N, Terry MA, Phillips PM. Busin glide vs forceps in Descemet stripping automated endothelial keratoplasty: not all forceps insertions are created equal. Am J Ophthalmol. 2009;148(1):175.

23. Beckingsale P, Mavrikakis I, Al-Yousuf N, Mavrikakis E, Daya SM. Penetrating keratoplasty: outcomes from a corneal unit compared with national data. Br J Ophthalmol. 2006;90(6):728-731.
24. Lim L, Pesudovs K, Coster DJ. Penetrating keratoplasty for keratoconus: visual outcome and success. Ophthalmology. 2000;107(6):1125-1131.

25. Barkana Y, Segal O, Krakovski D, Avni I, Zadok D. Prediction of visual outcome after penetrating keratoplasty for pseudophakic corneal edema. Ophthalmology. 2003;110(2):286-290.

26. Khor WB, Mehta JS, Tan DT. Descemet stripping automated endothelial keratoplasty with a graft insertion device: surgical technique and early clinical results. Am J Ophthalmol. 2011;151(2):223-232, e2.
Clinical Ophthalmology

\section{Publish your work in this journal}

Clinical Ophthalmology is an international, peer-reviewed journal covering all subspecialties within ophthalmology. Key topics include: Optometry; Visual science; Pharmacology and drug therapy in eye diseases; Basic Sciences; Primary and Secondary eye care; Patient Safety and Quality of Care Improvements. This journal is indexed on

\section{Dovepress}

PubMed Central and CAS, and is the official journal of The Society of Clinical Ophthalmology (SCO). The manuscript management system is completely online and includes a very quick and fair peer-review system, which is all easy to use. Visit http://www.dovepress.com/ testimonials.php to read real quotes from published authors. 